\title{
High Gyrodactylus salaris infection rate in triploid Atlantic salmon Salmo salar
}

\author{
M. Y. Ozerov ${ }^{1}$, J. Lumme' ${ }^{2}$, P. Päkk ${ }^{3}$, P. Rintamäki² ${ }^{2}$ M. S. Ziętara ${ }^{4}$, Y. Barskaya ${ }^{2}$, \\ D. Lebedevaa ${ }^{2}$, E. Saadre ${ }^{5}$, R. Gross ${ }^{3}$, C. R. Primmer ${ }^{1}$, A. Vasemägi ${ }^{1,3, *}$ \\ ${ }^{1}$ Department of Biology, 20014, University of Turku, Finland \\ ${ }^{2}$ Department of Biology, University of Oulu, 90014 Oulu, Finland \\ ${ }^{3}$ Department of Aquaculture, Institute of Veterinary Medicine and Animal Science, \\ Estonian University of Life Sciences, 51014 Tartu, Estonia \\ ${ }^{4}$ Laboratory of Comparative Biochemistry, Biological Station of University of Gdańsk, 80-680 Gdańsk, Poland \\ ${ }^{5}$ Põlula Fish Rearing Centre, Rägavere vald 46701, Estonia
}

\begin{abstract}
We describe an unusually high infection rate of Gyrodactylus salaris Malmberg in juvenile Atlantic salmon Salmo salar L. of Baltic Sea origin, which are generally believed to be more resistant to G. salaris than East Atlantic salmon populations. Based on analyses of mitochondrial (complete cytochrome oxidase 1 [CO1] gene, $1548 \mathrm{bp}$ ) and nuclear (ADNAM1, $435 \mathrm{bp}$; internal transcribed spacer [ITS] rDNA region, $1232 \mathrm{bp}$ ) DNA fragments, the closest relatives of the characterized Estonian G. salaris strain were parasites found off the Swedish west coast and in Raasakka hatchery, Iijoki (Baltic Sea, Finland). Analyses of 14 microsatellite loci of the host $S$. salar revealed that approximately $40 \%$ of studied fish were triploids. We subsequently identified triploid Atlantic salmon of Baltic origin as more susceptible to G. salaris infection than their diploid counterparts, possibly due to compromised complement-dependent immune pathways in triploid salmon. This is in accordance with earlier studies that have shown elevated susceptibility of triploids to various viral or bacterial pathogens, and represents one of the first reports of increased susceptibility of triploid salmonid fish to an ectoparasite. However, further experimental work is needed to determine whether triploid Atlantic salmon is generally more susceptible to G. salaris compared to their diploid counterparts, irrespective of the particular triploidization method and population of origin.
\end{abstract}

KEY WORDS: Atlantic salmon - Gyrodactylus salaris - Pathogen susceptibility · Triploid · Microsatellites · Baltic Sea

Resale or republication not permitted without written consent of the publisher

\section{INTRODUCTION}

Culture of triploid fish (i.e. individuals carrying 3 sets of chromosomes) has been used over the last $30 \mathrm{yr}$ as effective way of controlling sexual development in the fish farming industry (Dunham 2004). In salmonid aquaculture, triploidy has 2 main benefits: (1) it increases growth, carcass yield, and flesh quality by inhibiting gonadal development (Chourrout 1986, Dunham 1996, Gregory 2007); (2) in combination with other genetic manipulations it can prevent crossing of native wild fish with genetically modified or non-native stock (Dunham 2004, Gregory 2007). However, triploid salmon often exhibit higher mortality rates and higher incidence of de- formities (e.g. shortened opercula, jaw abnormalities), reduced gill surface area, and impaired oxygen carrying capacity due to the altered size and shape of the red blood cells (O'Flynn et al. 1997, Sadler et al. 2001). Triploidy can also affect the pathogen susceptibility/ resistance, and, in general, triploid salmonids appear to be less resistant to various pathogens than diploid fish (Dunham 2004). For example, triploid rainbow trout Oncorhynchus mykiss Walbaum are more susceptible to bacterial gill disease compared to diploid trout (Yamamoto \& Iida 1994). Similarly, Jhingan et al. (2003) found that triploid coho salmon $O$. kisutch Walbaum were more susceptible to vibriosis than their diploid counterpart. However, several studies have failed to de- 
tect significant differences in susceptibility between diploid and triploid fish. For example, both diploid and triploid rainbow trout exposed to Vibrio ordalii, Aeromonas salmonicida, or infectious hematopoietic necrosis virus demonstrated similar mortality rates (Yamamoto \& Iida 1995). Similar mortality rates between diploid and triploid Atlantic salmon were also observed after experimental infection with Renibacterium salmoninarum (Bruno \& Johnstone 1990).

Gyrodactylosis is a parasitic disease of salmonid fishes caused by the viviparous ectoparasite monogenean flatworm Gyrodactylus salaris, which belongs to the G. wageneri species-group, of the subgenus Limnonephrotus (family Gyrodactylidae, Malmberg, 1957). Due to 'hyperviviparity' (also known as a 'Russian doll' style of reproduction), combined with a rapid generation time, it reproduces fast, and in a matter of weeks a single worm can produce thousands of progeny (Bakke et al. 2007, Buchmann 2008). G. salaris damages fish not only by consuming mucus and epithelial cells of the host but also by piercing the fish epithelium with its hooklets, compromising its osmoregulatory function, and leaving it vulnerable to fungal and bacterial infections. Importantly, Atlantic salmon populations exhibit marked differences in susceptibility to G. salaris infection, with populations from the Atlantic and the White Sea coasts exhibiting higher infection rates and increased mortality, while salmon populations from the Baltic basin are more resistant to the parasite (Bakke et al. 1992, 2002, RintamäkiKinnunen \& Valtonen 1996, Dalgaard et al. 2003, Kuusela et al. 2009). The most severe G. salaris outbreaks have been observed in Norway, where epidemics of this parasite have devastated salmon stocks $>46$ rivers over the last 25 yr (Johnsen \& Jensen 1991, Johnsen et al. 1999, Bakke et al. 2007, Kuusela et al. 2007, 2009, Buchmann 2008). Despite the fact that Baltic salmon are generally believed to be more resistant to G. salaris, the susceptibility level varies among populations. For example, salmon populations from the Luleälven and Indalsälven rivers in Sweden (Bakke et al. 2002, 2004, Dalgaard et al. 2003) have been shown to be more susceptible to $G$. salaris infection than salmon populations from the Neva river in Russia and Tornio/Torne river along the border of Finland and Sweden (Bakke et al. 1990, 1992, Anttila et al. 2008). Moreover, the severity of infection also depends on the particular parasite strain (Lindenstrøm et al. 2003, Jørgensen et al. 2007, Kuusela et al. 2007, Ziętara et al. 2010). For example, outbreaks associated with rare clones of G. salaris have been recorded on Baltic salmon in fish farms (e.g. Rintamäki-Kinnunen \& Valtonen 1996, Kuusela et al. 2007). In a few cases it has been demonstrated that the farm parasites were species hybrids, such as G. pomeraniae $\times$ G. lavareti on rainbow trout (Kuusela et al. 2008), or unusual backcross combinations of G. salaris in Denmark (Lindenstrøm et al. 2003), Poland, and Macedonia (Ziętara et al. 2010) .

On 21 February 2008, a small number of Gyrodactylus sp. parasites were found during a routine parasitological inspection in a freshwater fish hatchery in northern Estonia among juvenile Atlantic salmon Salmo salar L. of 1+ yr old, originating from the Kunda river (Gulf of Finland, Baltic Sea). After 1 wk, the parasite prevalence reached $100 \%$, and the intensity of infection was much higher (from 10s to several 100s of parasites per individual fin) than commonly observed in Baltic salmon (Rintamäki-Kinnunen \& Valtonen 1996). This unusual level of $G$. salaris infection was alarming because of the possibility of a new, aggressively pathogenic parasite strain (Ziętara \& Lumme 2002, Kuusela et al. 2007). We subsequently genetically characterized both the host and the parasite in an attempt to gain more detailed insights into this unusually high G. salaris infection in supposedly resistant Baltic salmon. Based on analyses of mitochondrial cytochrome oxidase 1 (CO1) fragments and the variable nuclear marker ADNAM1, the parasite was genetically closely related to the $G$. salaris strains from the Gulf of Bothnia (Baltic Sea), and Swedish west coast (North Sea). Analyses of 14 microsatellite markers of the host confirmed its Baltic origin; however, it also revealed that a large proportion (ca. $40 \%$ ) of juvenile salmon carried 3 sets of chromosomes (i.e. were triploid) and the number of $G$. salaris found on triploid individuals was significantly higher than on their diploid counterparts.

\section{MATERIALS AND METHODS}

Sample collection and examination. On 21 February 2008, a small number of Gyrodactylus sp. parasites were found during a routine parasitological inspection in a freshwater fish hatchery in northern Estonia $(\mathrm{n}=4)$. In one particular tank 10 parasites per pectoral fin were observed in 2 examined juvenile Atlantic salmon of $1+\mathrm{yr}$ old (Kunda river origin). On 27-28 February 2008, a total of 586 hatchery-reared juvenile salmon (1+yr old) comprising 49 full-sib and half-sib families were sampled from the abovementioned $2 \mathrm{~m}$ diameter fish tank. This tank consisted of $1+\mathrm{yr}$ old Atlantic salmon of the smallest size, as these fish had been size-selected during routine hatchery practice (mean length: $24.12 \pm 9.94 \mathrm{~mm}$; mean weight: $12.95 \pm 1.94 \mathrm{~g}$ ). These fish were produced from the captive broodstock of Kunda river origin in autumn 2005 using a standard 'dry' artificial fertilization method. The fish were killed using MS-222 over- 
dose, and the right pectoral fin of every individual was stored separately in $96 \%$ ethanol, while the left pectoral fin was preserved in RNAlater $^{\circledR}$ (Ambion) for future gene expression analysis. Pectoral fins were chosen for subsequent analysis because $G$. salaris is most frequently ( $80 \%$ ) found on pectoral fins in Baltic salmon (Rintamäki-Kinnunen \& Valtonen 1996). The total number of parasites present on both sides of the alcohol-preserved pectoral fin was counted under a dissection microscope (10× magnification). In addition, a small number of pectoral and pelvic fins $(\mathrm{n}=32)$ were also examined from the fresh tissue using light microscopy (Leica CME) at $400 \times$ to 1000× magnification (see video of live G. salaris in Supplement 1, available at www.int-res.com/articles/ suppl/d091p129_supp1/).

DNA sequence analysis of parasite. DNA was isolated from single parasite specimens collected from individual hosts according to Ziętara et al. (2000). For molecular identification of the species and for phylogenetic characterization of the parasite, we sequenced the ITS rDNA with ITS1F and ITS2R primers (1232 bp), a 1623 bp long fragment encompassing complete mitochondrial cytochrome CO1 with Trp1F and Thr1R primers, and a 435 bp long variable nuclear marker ADNAM1 with InsF and InsR primers (Ziętara et al. 2006, Kuusela et al. 2007, 2009). These 3 loci have been successfully used to characterize both the interand intra-specific relationships within the genus Gyrodactylus (Ziętara \& Lumme 2002, Kuusela et al. 2007). Altogether, 2 ind. parasites collected from 2 different hosts were sequenced for the ITS; 3 parasites collected from 3 different hosts were sequenced for mtDNA CO1; and 9 parasites collected from 5 hosts were sequenced for nuclear anonymous DNA marker (ADNAM1). In addition, 32 parasites collected from 8 salmon were screened for ADNAM1 using agarose gel electrophoresis (Ziętara et al. 2006).

The mitochondrial and variable nuclear marker sequences were compared with earlier published Gyrodactylus salaris CO1 and ADNAM1 sequences (Kuusela et al. 2007, 2009). For clarification of isolated parasite strain genetic relationships with other strains, a Neighbor-joining tree (NJ tree) based on mtDNA CO1 sequence using maximum composite likelihood distance was constructed, with 1000 bootstrap replicates. The calculations were performed using the MEGA 4 program package (Tamura et al. 2007). The tree includes all well-characterized strains (complete CO1) of G. salaris found on Salmo salar, and the most close relatives on rainbow trout Oncorhynchus mykiss and Ohrid trout S. letnica Karaman (Kuusela et al. 2007). The tree is rooted with a sequence from a parasite on European grayling Thymallus thymallus L. from Hnilec river, Slovakia (Plaisance et al. 2007). The se- quences of G. salaris were deposited in GenBank under accession numbers GU187353 (ITS rDNA), GU187354 (mtDNA CO1), and GU187355 (ADNAM1).

Microsatellite DNA analysis of host. After the examination of the parasite, host DNA was extracted from 111 Atlantic salmon specimens using the right pectoral fin clips according to Elphinstone et al. (2003), with slight modifications as described in Tonteri et al. (2009). Three separate multiplex polymerase chain reactions (PCR) were used to amplify 14 polymorphic Atlantic salmon microsatellites as described in Tonteri et al. (2009). PCR products of each of the 3 multiplexes were pooled together and genotyped using an ABI Prism 3130xl Genetic Analyzer (Applied Biosystems). The internal size standard GS600LIZ (Applied Biosystems) was used to define microsatellite allele sizes. DNA fragments were analyzed and genotypes were scored with GENEMAPPER 4.1 software (Applied Biosystems). Based on the multi-locus genotype profiles of microsatellite loci, it was possible to efficiently separate diploid and triploid individuals, as diploid specimens possessed either 1 or 2 alleles per locus, while triploid fish exhibited 3 alleles in at least 1 locus out of 14 (Supplement 2, available at www.int-res.com/ articles/suppl/d091p129_supp2.pdf). Importantly, we never observed more than 3 alleles per locus, which might indicate contamination of the samples (i.e. mixture of 2 or more diploid individuals). In addition, we repeated DNA isolation according to Laird et al. (1991) using the left pectoral fin and re-genotyped ca. $10 \%$ of triploid individuals to evaluate the repeatability of multi-locus genotype profiles.

Statistical analyses. The difference in number of parasites on the upper and lower sides of the pectoral fin ( $\mathrm{n}=586)$, as well as on the pectoral and pelvic fin for a subset of salmon individuals ( $\mathrm{n}=32$ ), was tested using a non-parametric Wilcoxon signed-rank test. The dependence of the intensity of infection (number of Gyrodactylus salaris on the right pelvic fin of the host) on the host ploidy level was tested using a nonparametric Mann-Whitney test. As the growth rates of diploid and triploid fish are rarely similar (Dunham 2004), we tested whether the size of diploid and triploid 1+ yr old salmon juveniles differ from each other using a non-parametric Mann-Whitney test. All tests were carried out using SPSS for Windows, version 11.

\section{RESULTS}

\section{Parasite abundance}

The estimated prevalence of infection was $100 \%$, and mean intensity of Gyrodactylus salaris was 85 
parasites per pectoral fin. The total number of $G$. salaris counted on a single pectoral fin of the host varied from 1 to 855 across 586 ind., and 147 juvenile salmon $(25 \%)$ had $>100$ parasites per fin (Fig. 1). The number of parasites was higher on the upper side of the pectoral fin compared to the lower side (median: 31 and 22, respectively; Wilcoxon signed-rank test, $\mathrm{p}<0.001)$. There was also significant correlations between the number of parasites found on the upper and lower side of the pectoral fin ( $\mathrm{n}=586$, Spearman's rank correlation coefficient $r_{S}=0.402, p<0.01$ ) and between the number of parasites on pelvic and pectoral fins ( $\mathrm{n}=32$, Spearman's rank correlation coefficient $\left.r_{S}=0.430, p<0.05\right)$. More parasites were observed on pectoral fins compared to pelvic fins ( $\mathrm{n}=$ 32) (median: 55 and 31, respectively; Wilcoxon signed-rank test, $\mathrm{p}<0.01$ ).

\section{Molecular identification and phylogenetic characterization of the parasite}

Based on analyses of ITS rDNA sequence, the parasite was identified unambiguously as Gyrodactylus salaris Malmberg. When mitochondrial CO1 sequences were compared with earlier G. salaris sequences (Kuusela et al. 2007, 2009), the mtDNA CO1 haplotypes genetically closest to the Estonian G. salaris were parasite strains from Raasakka hatchery, Iijoki, Finland, and from the Genevadsån river, Swedish west coast (Fig. 2). The CO1 sequence of the Estonian G. salaris differed from these strains by only a single nucleotide. The nuclear ADNAM1 genotype of Estonian strain was S4 (TMRTYRTAT, consisting of alleles TCATTGTAT [BS5] and TAGTCATAT [WS3]). This ADNAM1 combination and the allele BS5 have been found before in parasites on the Swedish west coast (Fig. 2). G. salaris strains found in landlocked salmon populations from Lakes Ladoga and Onega, on the other hand, were genetically more distant from the Estonian strain (Kuusela et al. 2007, 2009). More detailed information about the relationships between different ADNAM1 alleles can be found in Kuusela et al. (2007).

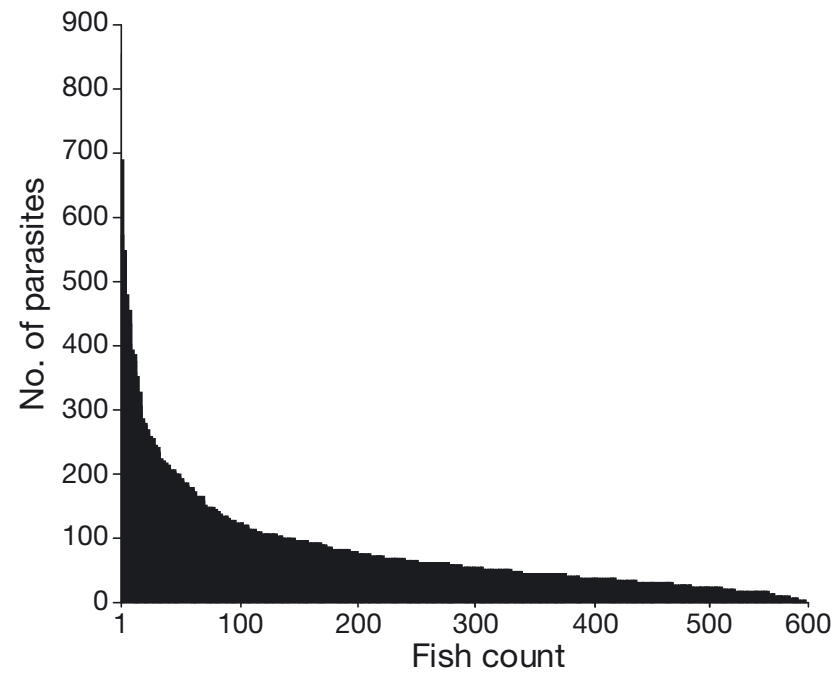

Fig. 1. Distribution of parasites in 586 studied Atlantic salmon (number of Gyrodactylus salaris on the right pelvic fin of the host)
mtDNA CO1

ADNAM1

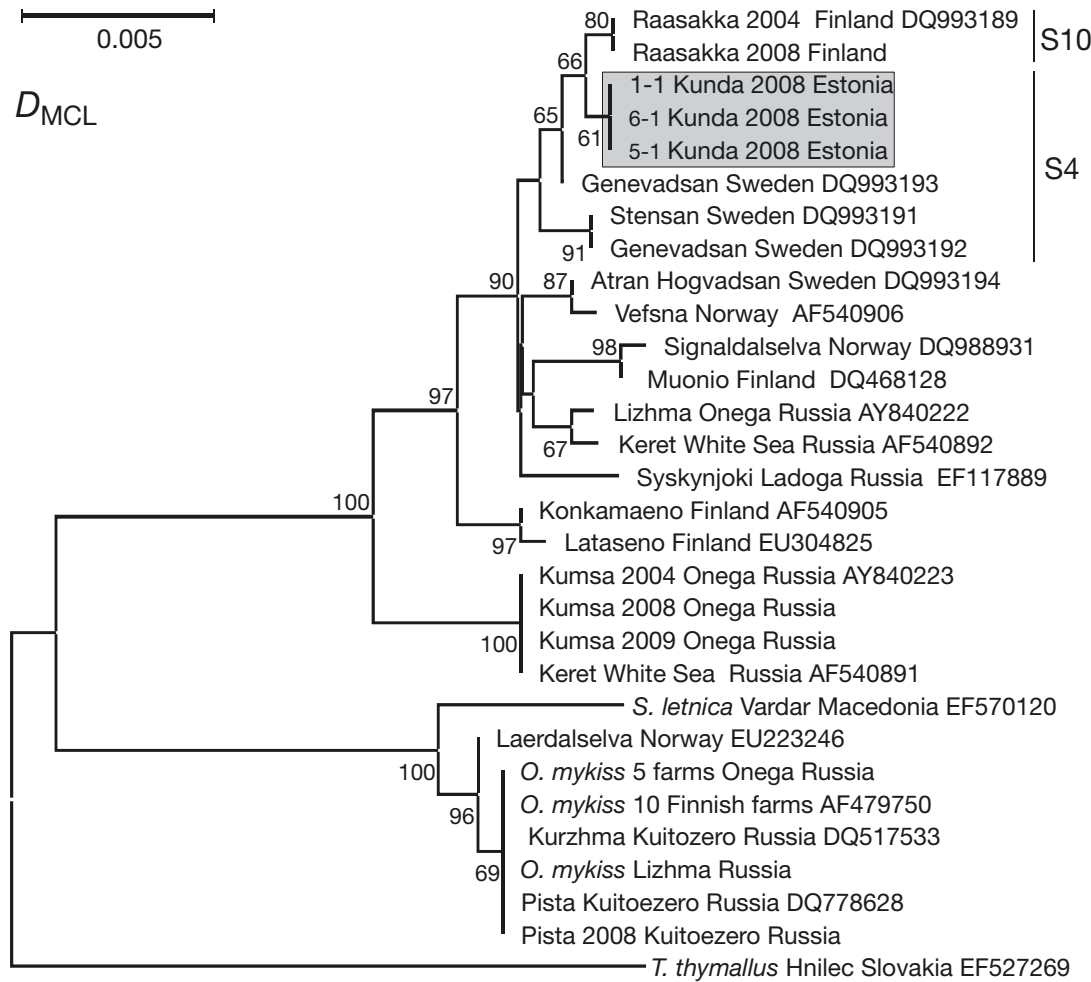

Fig. 2. Neighbor-joining tree based on maximum composite likelihood distance $\left(D_{\mathrm{MCL}}\right)$ of the mtDNA CO1 gene (1548 bp). Haplotypes of Estonian Gyrodactylus salaris strain are marked in grey. The tree includes all well-characterized strains of G. salaris found on Salmo salar, and the closest relatives on rainbow trout Oncorhynchus mykiss and Ohrid trout S. letnica (Kuusela et al. 2007). The tree is rooted with a sequence from a parasite on European grayling Thymallus thymallus from the Hnilec river, Slovakia (Plaisance et al. 2007). Two nuclear genotypes of ADNAM1 marker (S4 and S10) are shown in the upper right corner 


\section{Ploidy of host and elevated susceptibility of triploid Atlantic salmon}

Microsatellite analyses of Atlantic salmon confirmed its Baltic origin (data not shown), but also revealed that about $40 \%$ of analyzed individuals possessed 3 alleles at least in 1 locus out of 14 (Supplement 2). Repeated DNA extraction and re-genotyping of about $10 \%$ of specimens indicated that these multi-locus genotype profiles were highly repeatable and never possessed $>3$ locus alleles per marker. As a result, we inferred that juvenile salmon exhibiting 3 alleles per locus most likely carry 3 sets of chromosomes (i.e. were triploid). Subsequent evaluation of multi-locus genotypes revealed that triploid individuals most likely originated from several families as they possessed a large number of different allele combinations (Supplement 2). For example, triploid individuals carried altogether 10 alleles at the most variable microsatellite locus SSOSL311, which is consistent with multiple triploid family scenario. The parasite load was significantly higher in triploid salmon than in diploid fish (Fig. 3; median: 65 and 46, respectively; Mann-Whitney test, $p=0.003)$. The length and weight, on the other hand, did not differ between triploid and diploid fish (Mann-Whitney test, $p$ values of both tests $>0.16$ ).

\section{DISCUSSION}

In the present study we genetically characterized both the host and parasite to further understand the unusually high level of Gyrodactylus salaris infection on Baltic salmon in an Estonian fish hatchery. Such elevated levels of parasite abundance were rather unexpected as Baltic salmon is generally believed to be re-

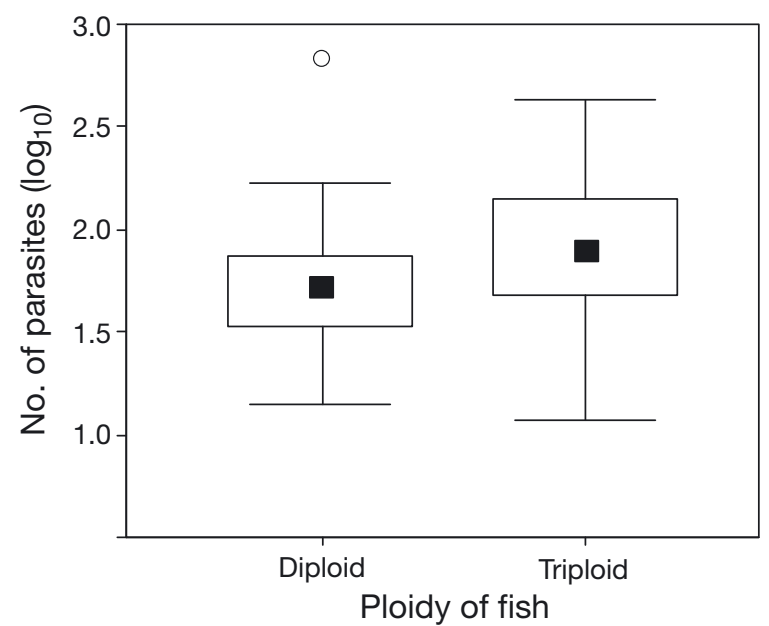

Fig. 3. Number of Gyrodactylus salaris parasites ( $\log _{10}$ scale) in diploid and triploid host Salmo salar (Mann-Whitney test, $\mathrm{p}=0.003$ ). $\mathbf{\square}$ : median; O: outlier. Open rectangle and whiskers 25th and 75th quartiles and non-outlier range, respectively sistant to G. salaris (Bakke et al. 1992, 2002, RintamäkiKinnunen \& Valtonen 1996, Anttila et al. 2008). For example, the number of parasites observed on Baltic salmon in Finnish hatcheries has been typically very low (1 to 5 per fish in most cases; Rintamäki-Kinnunen \& Valtonen 1996). However, mean intensity of G. salaris observed in an Estonian fish hatchery was as high as 85 parasites per pectoral fin. The closest relatives of the Estonian G. salaris strain were parasites found in Genevadsån, Swedish west coast (North Sea), and in Raasakka hatchery, Iijoki (Gulf of Bothnia, Finland), showing one nucleotide difference in the $\mathrm{CO} 1$ region of mtDNA. Moreover, the combination of alleles at the nuclear ADNAM1 marker was identical to that found in parasites on the Swedish west coast. Therefore, it is likely that the described parasite strain is native to the Baltic Sea and exists in the wild salmon populations in Estonia, as the Atlantic west coast parasites found in Sweden are believed to originate from the Baltic (e.g. Hansen et al. 2003). Consequently, analyses of $G$. salaris collected in Estonian rivers could provide further information about distribution and prevalence of this strain. To our knowledge, G. salaris has never been reported in Estonian rivers, suggesting that it is generally harmless in the wild (Kuusela et al. 2009).

Subsequent analyses of microsatellite loci of the host Salmo salar revealed that about $40 \%$ of the analyzed individuals were triploids, and we observed highly significant differences in parasite load between triploid and diploid fish suggesting that high Gyrodactylus salaris infection rate in this particular case was most likely triggered by the triploidy of the host. Hence, it is possible that increased $G$. salaris susceptibility of triploid Atlantic salmon is related to compromised complement-dependent immune pathways in triplod fish, as several earlier studies have demonstrated the important role of complement (C3) in protection against G. salaris in salmonid fishes (Moore et al. 1994, Buchmann 1998, Harris et al. 1998, Bakke et al. 2002). As a result, it may take a longer time to recover complement activity for triploid salmon (Langston et al. 2001). This is also in accordance with earlier studies that have demonstrated elevated susceptibility of triploid salmonids to various viral or bacterial pathogens (Yamamoto \& Iida 1994, 1995, Jhingan et al. 2003, Dunham 2004). However, triploidy of the host does not always result in increased parasite abundance, as similar susceptibility to Gyrodactylus sp. has been observed in diploid and triploid tench Tinca tinca L. (Piaãková \& Flajšhans 2006).

How can the occurrence of triploid fish in this hatchery be explained? Triploidy in fishes is commonly induced artificially by forcing retention of the second polar body after normal fertilization that yields fusion of nuclei from egg, sperm, and second polar body 
(Chourrout 1980, 1984, Lou \& Purdom 1984). The number of different alleles at a specific locus in triploids depends on the genotype of both parents and the crossing-over frequency during the first meiotic division of primary oocytes. Thus, the triploids can possess either 1,2, or even 3 alleles at a specific locus. Retention of the second polar body can be achieved by applying hydrostatic pressure, anesthetics, temperature, $\mathrm{pH}$, or chemical shocks shortly after fertilization (Thorgaard et al. 1981, Chourrout \& Itskovich 1983, Benfey \& Sutterlin 1984, Cassani \& Caton 1986, Curtis et al. 1987, Ueda et al. 1988, Johnstone et al. 1989). Alternatively, triploids can be obtained by fertilization of diploid eggs of tetraploid fish by haploid sperm of diploid fish (Chourrout et al. 1986). However, neither of these techniques has ever been used in the Estonian fish hatchery in question. Triploids can also be produced when hybridization and backcrossing occurs between Atlantic salmon and brown trout Salmo trutta L. (e.g. Johnson \& Wright, 1986). This can be excluded, however, as we did not observe any trout-specific microsatellite alleles within the $1+\mathrm{yr}$ old fish, and additional genetic analyses of the parents ( 47 females and 33 males) did not reveal any alleles diagnostic for trout (data not shown). In addition, microsatellite analyses of the subsequent hatchery cohort $(n=722)$ created using the same parental fish (eggs fertilized in 2007) did not reveal any triploid specimens (data not shown). As a result, we were not able to identify the exact mechanism of 'spontaneous' production of triploid Atlantic salmon from the diploid salmon broodstock. However, a low frequency of 'spontaneous' occurrence of triploid individuals in fish has been previously reported (Chourrout 1980). As to the question of why the infection level was also elevated in diploid juveniles, we suggest that by continuous exchange of the worms, the more resistant diploid fish in the same tank were probably loaded by the surplus of parasites, which explains the high overall intensity of infection.

In the present study we used highly variable microsatellite markers to determine the ploidy of juvenile salmon, but there exist a large number of alternative methods that have been used previously for detection of triploid individuals. Traditionally, triploid fish have been identified using karyotyping, cell-size measurement with a Coulter Counter Channelyzer, or by using blood smears, silver staining of nucleoar organizing regions (NORs), or flow cytometry (Dunham 2004). Earlier works also demonstrated the utility of dimeric isozymes for determination of triploid individuals (Sugama et al. 1988, Crozier \& Moffet 1990). The use of highly polymorphic microsatellite markers for detection of triploid individuals, however, has a number of advantages compared to less variable isozymes and other traditional methods, such as the ability to use fixed or old samples of any tissue for DNA isolation, the possibility for non-invasive sampling, and the availability of a large number of polymorphic markers in many species. On the other hand, the limitations of the use of microsatellite markers for triploid detection include potential misclassification of triploid fish as diploids (type II error) due to low variability or when a relatively low number of markers is used. However, in the present study we used 14 highly polymorphic microsatellite markers consisting in total of 100 alleles, and, therefore, it is unlikely that we have misclassified triploid fish as diploids. Furthermore, misclassification would make our results even more conservative, as this would reduce the difference in parasite abundance between triploid and diploid fish.

In conclusion, we described an unusual Gyrodactylus salaris infection in a hatchery population of Baltic salmon, phylogenetically characterized the G. salaris strain showing that it was genetically closest to other strains of Baltic origin, and demonstrated that triploid Atlantic salmon were more susceptible to G. salaris infection than their diploid counterparts, probably due to compromised complement-dependent immune pathway. This is in accordance with earlier studies that have shown elevated susceptibility of triploids to various viral or bacterial pathogens and represents one of the first reports of increased susceptibility of triploid salmonid host to an ectoparasite. However, future work is needed to determine the generality of our finding, e.g. whether triploid Atlanic salmon is generally more susceptible to G. salaris compared to their diploid counterparts, irrespective of the particular triploidization method (e.g. andro- or gynogenesis induced by physical or chemical factors) and population of origin.

Acknowledgements. This work was financed by the Estonian Science Foundation (grant no. 6802, 8215, 5729), targeted finance grant SF1080022s07, and supported by the Academy of Finland. We thank V. Aukee during sampling and give special thanks to the staff of Põlula Fish Rearing Center for their great support.

\section{LITERATURE CITED}

Anttila P, Romakkaniemi A, Kuusela J, Koski P (2008) Epidemiology of Gyrodactylus salaris (Monogenea) in the River Tornionjoki, a Baltic wild salmon river. J Fish Dis 31:373-382

Bakke TA, Jansen PA, Hansen LP (1990) Differences in the host resistance of Atlantic salmon (Salmo salar) stocks to the monogenean Gyrodactylus salaris Malmberg, 1957. J Fish Biol 37:577-587

$>$ Bakke TA, Harris PD, Jansen PA, Hansen LP (1992) Host specificity and dispersal strategy in gyrodactylid monogeneas, with particular reference to Gyrodactylus salaris (Platyhelmintes, Monogenea). Dis Aquat Org 13:63-74 
Bakke TA, Harris PD, Cable J (2002) Host specificity dynamics: observations on gyrodactylid monogeneans. Int J Parasitol 32:281-308

Bakke TA, Harris PD, Hansen H, Cable J, Hansen LP (2004) Susceptibility of Baltic and East Atlantic salmon Salmo salar stocks to Gyrodactylus salaris (Monogenea). Dis Aquat Org 58:171-177

Bakke TA, Cable J, Harris PD (2007) The biology of gyrodactylid monogeneans: the 'Russian-doll killers'. Adv Parasitol 64:161-376

Benfey TJ, Sutterlin AM (1984) Triploidy induced by heat shock and hydrostatic pressure in landlocked Atlantic salmon (Salmo salar L.). Aquacult 36:359-367

Bruno DW, Johnstone R (1990) Susceptibility of diploid and triploid Atlantic salmon. Bull Eur Assoc Fish Pathol 10: 45-47

Buchmann K (1998) Binding and lethal effect of complement from Oncorhynchus mykiss on Gyrodactylus derjavini (Platyhelminthes: Monogenea). Dis Aquat Org 32: 195-200

Buchmann K (2008) Along for the ride: a parasitic threat to northern European salmon. ICES Insight 45:12-15

> Cassani JR, Caton WE (1986) Efficient production of triploid grass carp (Ctenopharyngodon idella) utilizing hydrostatic pressure. Aquacult 55:43-50

Chourrout D (1980) Thermal induction of diploid gynogenesis and triploidiy in the eggs of the rainbow trout (Salmo gairdneri Richardson). Reprod Nutr Dev 20:727-733

Chourrout D (1984) Pressure induced retention of second polar body and suppression of first cleavage in rainbow trout: production of all-triploids, all-tetraploids and heterozygous and homozygous diploid gynogenetics. Aquaculture 36:111-126

Chourrout D (1986) Techniques of chromosome manipulation in rainbow trout: a new evaluation with karyology. Theor Appl Genet 72:627-632

Chourrout D, Itskovich J (1983) Three manipulations permitted by artificial insemination in tilapia: induced diploid gynogenesis, production of all-triploid populations and intergeneric hybridization. In: Fishelson L, Yaron Z (comps) International symposium on tilapia in aquaculture. Tel Aviv University

Chourrout D, Chevassus B, Krieg F, Happe A, Burger G, Renard P (1986) Production of second generation triploid and tetraploid rainbow trout by mating tetraploid males and diploid females. Potentials of tetraploid fish. Theor Appl Genet 72:193-206

> Crozier WW, Moffett IJJ (1990) Inheritance of allozymes in Atlantic salmon (Salmo salar L.). Aquaculture 88:253-262

Curtis TA, Sessions FW, Bury D, Rezk M, Dunham RA (1987) Induction of polyploidy in striped bass, white bass and their hybrids with hydrostatic pressure. Proc Annu Conf Southeast Assoc Fish Wildlife Agencies 41:63-69

Dalgaard MB, Nielsen CV, Buchmann K (2003) Comparative susceptibility of two races of Salmo salar (Baltic Lule River and Atlantic Conon River strains) to infection with Gyrodactylus salaris. Dis Aquat Org 53:173-176

Dunham RA (1996) Contribution of genetically improved aquatic organisms to global food security. In: International conference on sustainable contribution of fisheries to food security. Government of Japan and FAO, Rome

Dunham RA (2004) Aquaculture and fisheries biotechnology: Genetic approaches. CAB International, Cambridge

- Elphinstone MS, Hinten GN, Anderson MJ, Nock CJ (2003) An inexpensive and high-throughput procedure to extract and purify total genomic DNA for population studies. Mol Ecol Notes 3:317-320
Gregory NG (2007) Animal welfare and meat production. 2nd edn. BBSRC and Royal Veterinary College, UK. CAB International, Cambridge

Hansen H, Bachmann L, Bakke TA (2003) Mitochondrial DNA variation of Gyrodactylus spp. (Monogenea, Gyrodactylidae) populations infecting Atlantic salmon, grayling, and rainbow trout in Norway and Sweden. Int J Parasitol 33: 1471-1478

Harris PD, Soleng A, Bakke TA (1998) Killing of Gyrodactylus salaris (Platyhelminthes, Monogenea) mediated by host complement. Parasitol 117:137-143

Jhingan E, Devlin RH, Iwama GK (2003) Disease resistance, stress response and effects of triploidy in growth hormone transgenic coho salmon. J Fish Biol 63:806-823

Johnsen BO, Jensen AJ (1991) The Gyrodactylus story in Norway. Aquacult 98:289-302

Johnsen BO, Møkkelgjerd PI, Jensen AJ (1999) The parasite Gyrodactylus salaris on salmon parr in Norwegian rivers, status report at the beginning of year 2000. NINA Oppdragsmeld 617:1-129 (in Norwegian, English summary)

> Johnson KR, Wright JE (1986) Female brown trout $\times$ Atlantic salmon hybrids produce gynogens and triploids when backcrossed to male Atlantic salmon. Aquaculture 57: 345-358

Johnstone R, Knott RM, MacDonald AG, Walsingham MV (1989) Triploidy induction in recently fertilized Atlantic salmon ova using anaesthetics. Aquacult 78:229-236

Jørgensen TR, Larsen TB, Jørgensen LG, Bresciani J, Kania PW, Buchmann K (2007) Characterization of a low pathogenic form of Gyrodactylus salaris from rainbow trout. Dis Aquat Org 73:235-244

Kuusela J, Ziętara MS, Lumme J (2007) Hybrid origin of Baltic salmon-specific parasite Gyrodactylus salaris: a model for speciation by host switch for hemiclonal organisms. Mol Ecol 16:5234-5245

Kuusela J, Ziętara MS, Lumme J (2008) Description of three new European cryptic species of Gyrodactylus Nordmann, 1832 supported by nuclear and mitochondrial phylogenetic characterization. Acta Parasitol 53:120-126

Kuusela J, Holopainen R, Meinilä M, Anttila P and others (2009) Clonal structure of salmon parasite Gyrodactylus salaris on a coevolutionary gradient on Fennoscandian salmon (Salmo salar). Ann Zool Fenn 46:21-33

- Laird PW, Zijderveld A, Linders K, Rudnicki MA, Jaenisch R, Berns A (1991) Simplified mammalian DNA isolation procedure. Nucleic Acids Res 19:4293

> Langston AL, Johnstone R, Ellis AE (2001) The kinetics of the hypoferraemic response and changes in levels of alternative complement activity in diploid and triploid Atlantic salmon, following injection of lipopolysaccharide. Fish Shellfish Immunol 11:333-345

> Lindenstrøm T, Collins CM, Bresciani J, Cunningham CO, Buchmann K (2003) Characterization of a Gyrodactylus salaris variant: infection biology, morphology and molecular genetics. Parasitology 127:165-177

> Lou YD, Purdom CE (1984) Polyploidy induced hydrostatic pressure in rainbow trout, Salmo gairdneri Richardson. J Fish Biol 25:345-357

Moore MM, Kaattari SL, Olson RE (1994) Biologically active factors against the monogenetic trematode Gyrodactylus stellatus in the serum and mucus of infected juvenile English soles. J Aquat Anim Health 6:93-100

O'Flynn FM, McGeachy SA, Friars GW, Benfey TJ, Bailey JK (1997) Comparisons of cultured triploid and diploid Atlantic salmon (Salmo salar L.). ICES J Mar Sci 54: 1160-1165 
Piaãková V, Flajšhans M (2006) Long-term examination of health conditions in monoculture of communally tested amphimictic diploid, diploid gynogenic and triploid tench, Tinca tinca (L.). Aquacult Int 14:43-59

Plaisance L, Huyse T, Littlewood DT, Bakke TA, Bachmann L (2007) The complete mitochondrial DNA sequence of the monogenean Gyrodactylus thymalli (Platyhelminthes: Monogenea), a parasite of grayling (Thymallus thymallus). Mol Biochem Parasitol 154:190-194

Rintamäki-Kinnunen P, Valtonen ET (1996) Finnish salmon resistant to Gyrodactylus salaris: a long-term study at fish farms. Int J Parasitol 26:723-732

Sadler J, Pankhurst PM, King HR (2001) High prevalence of skeletal deformity and reduced gill surface area in triploid Atlantic salmon (Salmo salar L.). Aquaculture 198:369-386

Sugama K, Taniguchi N, Arakawa T, Kitajima C (1988) Isozyme expression of artificially induced ploidy in red sea bream, black sea bream and their hybrid. In: Report No. 10. US Marine Biology Institute, Kochi University/ Kochidai Kaiyoseibutsu Kenpo, p 75-81

Tamura K, Dudley J, Nei M, Kumar S (2007) MEGA4: Molecular Evolutionary Genetics Analysis (MEGA) software version 4.0. Mol Biol Evol 24:1596-1599

Thorgaard GH, Jazwin ME, Stier AR (1981) Polyploidy induced by heat shock in rainbow trout. Trans Am Fish Soc 110:546-550

Tonteri A, Veselov AJ, Zubchenko A, Lumme J, Primmer C (2009) Microsatellites reveal clear genetic boundaries

Editorial responsibility: Alex Hyatt,

Geelong, Victoria, Australia among Atlantic salmon (Salmo salar L.) populations from Barents and White seas. Can J Fish Aquat Sci 66: 717-735

Ueda T, Sato R, Kobayashi J (1988) Triploid rainbow trout induced by high-pH multiplied by high-calcium. Nippon Suisan Gakkaishi (Bull Jpn Soc Sci Fish) 54:2045

Yamamoto A, Iida T (1994) Hematological characteristics of triploid rainbow trout. Fish Pathol 29:239-243

Yamamoto A, Iida T (1995) Susceptibility of triploid rainbow trout to IHN, furunculosis and vibriosis. Fish Pathol 30: $69-70$

Ziętara MS, Lumme J (2002) Speciation by host switch and adaptive radiation in a fish parasite genus Gyrodactylus (Monogenea, Gyrodactylidae). Evolution 56:2445-2458

Ziętara MS, Arndt A, Geets A, Hellemans B, Volckaert FAM (2000) The nuclear rDNA region of Gyrodactylus arcuatus and G. branchicus (Monogenea: Gyrodactylidae). J Parasitol 86:1368-1373

Ziętara MS, Kuusela J, Lumme J (2006) Escape from an evolutionary dead-end: a triploid clone of Gyrodactylus salaris is able to revert to sex and switch host (Platyhelminthes, Monogenea, Gyrodactylidae). Hereditas 143: 86-92

Ziętara MS, Rokicka M, Stojanowski S, Lumme J (2010) Introgression of distant mitochondria into the genome of Gyrodactylus salaris: nuclear and mitochondrial markers are necessary to identify parasite strains. Acta Parasitol 55: 20-28

Submitted: November 25, 2009; Accepted: May 10, 2010 Proofs received from author(s): July 19, 2010 